\title{
Arriscar ao brincar: análise das perceções de risco em relação ao brincar num grupo de educadoras de infância
}

MARIA GABRIELA PORTUGAL BENTO

Universidade de Aveiro, Aveiro, Portugal

RESUMO

Assumindo que o brincar arriscado apresenta benefícios para o desenvolvimento e a aprendizagem das crianças, a investigação apresentada pretende explorar as perceções de risco num grupo de 13 educadoras de infância portuguesas. Esse grupo profissional exerce uma grande influência no tipo de experiências que são oferecidas às crianças, numa fase da vida em que o brincar se assume como meio potenciador do desenvolvimento. Por meio de entrevistas semiestruturadas, articuladas com imagens representativas de diferentes experiências do brincar arriscado (Sandseter, 2007, 2009a), procuramos perceber de que maneira as situações de risco são interpretadas e quais os ganhos que estas podem trazer para o desenvolvimento infantil. Concluímos que, entre as participantes, o risco no brincar é dificilmente aceito, ponderando-se diferentes dimensões na avaliação da situação. Apesar de o brincar arriscado não ser promovido, as educadoras reconhecem a existência de ganhos para o desenvolvimento.

PALAVRAS-CHAVE

perceções de risco; brincar; espaços exteriores; educação infantil. 


\title{
PLAYING AND TAKING RISKS: ANALYSIS OF RISKY PLAY PERCEPTIONS IN A GROUP OF EARLY CHILDHOOD TEACHERS
}

\begin{abstract}
Recognizing the benefits of risky play for learning and development of children, this research aims to explore risky play perceptions in a group of 13 Portuguese early childhood teachers. This professional group was chosen due to the meaningful influence they have in the type of experiences that children come across in a stage of life where play is an important promoter of global development. Using semi structured interviews, articulated with images of risky play (Sandseter, 2007, 2009a), we tried to understand how risky play situations are interpreted and what are the main gains for children development. Our findings show that in the group of early childhood teachers interviewed risky play is hardly accepted and their evaluation is influenced by different dimensions. Although risky play is not promoted, early childhood teachers recognized benefits in these experiences.
\end{abstract}

\section{KEYWORDS}

risk perception; play; outdoor spaces; early childhood education.

\section{JUEGO ARRIESGADO: ANÁLISIS DE LAS PERCEPCIONES DE RIESGO EN UN GRUPO DE EDUCADORES DE LA PRIMERA INFANCIA}

\section{RESUMEN}

Reconociendo que el juego arriesgado tiene beneficios para el aprendizaje y desarrollo de los niños, esta investigación tiene como objetivo explorar las percepciones de riesgo en un grupo de 13 educadores de la primera infancia portugueses. Este grupo profesional tiene una gran influencia en el tipo de experiencias que se ofrecen a los niños en una etapa de la vida en que se reconoce que el juego es muy importante para el desarrollo. A través de entrevistas semi-estructuradas, articuladas con imágenes que representan las diferentes experiencias de juego arriesgado (Sandseter, 2007, 2009a), hemos tratado de entender cómo se interpretan las situaciones de riesgo y qué ganancias pueden llevar al desarrollo. Llegamos a la conclusión de que, entre los profesores entrevistados, el riesgo en el juego casi no se aceptó, con un peso de hasta diferentes dimensiones para evaluar la situación. A pesar de juego arriesgado no ser promovido, los educadores reconocen la existencia de ganancias para el desarrollo.

PALABRAS CLAVE

percepciones de riesgo; juego; espacios al aire libre; educación infantil. 


\section{INTRODUÇÃO}

Durante a infância, os diferentes estímulos que surgem no dia a dia das crianças apresentam-se como potenciadores de novas experiências, por meio das quais se desenvolvem competências e conhecimentos. Nesse processo, o brincar pode ser compreendido como uma via privilegiada para lidar com diferentes desafios, assumindo-se como meio de aprendizagem e de desenvolvimento (Fjørtoft ,2004; Thomas; Harding, 2011).

Reconhecendo-se uma relação estreita entre as características dos contextos e o tipo de experiências que a criança conhece, brincar nos espaços exteriores assume-se como uma atividade significativa, que oferece importantes oportunidades de exploração, aventura e contacto com a natureza.

Contudo, estudos realizados revelam que o brincar das crianças tem vindo a assumir um carácter cada vez mais estruturado, circunscrito a espaços fechados, controlado pelos adultos, em que as possibilidades de ação da criança são limitadas (Neto, 1997, 2005; Tovey, 2007). Verifica-se uma tendência para manter a criança intelectualmente ativa e corporalmente passiva, numa fase em que o jogo espontâneo e a atividade física são muito importantes para o desenvolvimento de uma vida ativa, pautada por hábitos saudáveis (Neto, 1997; Thigpen, 2007).

A esse cenário associam-se problemas relacionados com a saúde infantil. De acordo com a Organização Mundial de Saúde (OMS) (2006), uma em cada cinco crianças do espaço europeu tem excesso de peso, sendo que esses valores parecem estar a aumentar a uma velocidade preocupante. Em Portugal, segundo estudo realizado por Rito e Breda (2010), no âmbito WHO - European Childhood Obesity Surveillance Initiative, entre 6 e 9 anos, regista-se uma prevalência de pré-obesidade de $17,6 \%$ e obesidade de $14,5 \%$, o que perfaz um total de $32,1 \%$ de crianças com excesso de peso. No mesmo sentido apontam os dados da investigação realizada por Albuquerque e colaboradores (2012), com crianças entre 6 e 12 anos da região centro de Portugal, em que se registou uma prevalência de excesso de peso de $33 \%$, entre as quais $10,7 \%$ eram obesas. A obesidade infantil está relacionada com outro tipo de problemas de saúde, como a diabetes, a hipertensão ou problemas cardiovasculares, que se agravam na idade adulta e prejudicam a qualidade de vida. Durante a infância e adolescência, é também possível relacionar o excesso de peso com situações de baixa autoestima, reduzida confiança nas capacidades pessoais e significativas dificuldades nas relações sociais (Tovey, 2007).

A diminuição de experiências de brincar ao ar livre, em contacto com a natureza, surge associada à crescente expansão do mundo digital, que fascina as crianças e as mantém ligadas às telas, ao aumento da densidade automóvel e à crescente urbanização de espaços que outrora eram utilizados para brincar. Ainda, verifica-se uma grande insegurança por parte dos pais perante os perigos a que as crianças podem estar sujeitas, que se traduz numa maior necessidade de proteção. As experiências de brincar na rua ou de ir a pé para a escola passam a ser substituídas por trajetos de carro até locais onde se desenvolvem atividades institucionalizadas, por vezes confinadas a espaços fechados, que limitam os movimentos e as possibilidades de expressão corporal (Moreno, 2009; Neto, 2005). 
Nesse âmbito, o presente artigo pretende explorar a temática do risco no brincar enquanto dimensão estreitamente relacionada com as vivências das crianças nos espaços exteriores. Assumindo-se o risco presente em experiências diversificadas de aventura e desafio como um fator potenciador de desenvolvimento, e a excessiva segurança como um perigo para esse mesmo desenvolvimento, a investigação realizada procurou explorar as perceções de risco no brincar de um grupo de educadoras de infância. Atendendo ao longo período de tempo que cada criança passa diariamente no jardim de infância, torna-se possível considerar que os adultos que nele participam têm uma influência significativa no tipo de experiências a que as crianças têm acesso, podendo ser promotores ou inibidores de atividades que envolvem a exploração dos espaços exteriores e as experiências de risco no brincar.

\section{INFLUÊNCIA DO BRINCAR ARRISCADO NO DESENVOLVIMENTO E APRENDIZAGEM DAS CRIANÇAS}

$\mathrm{Na}$ sociedade atual, em prol da proteção e segurança das crianças, o risco é muitas vezes compreendido como algo que deve ser removido, ignorando-se a sua influência no brincar e no desenvolvimento da criança (Tovey, 2011).

Little e Eager (2010) consideram que o risco surge representado em situações que exigem a realização de escolhas entre diferentes alternativas de ação, cujo resultado é desconhecido. Pode ser considerado um contínuo que não está inevitavelmente associado a consequências negativas. Na perspetiva desses autores, risco distingue-se de perigo, noção que é aplicada em situações cuja probabilidade de dano é elevada e que podem conduzir a ferimentos graves ou à morte.

Segundo Adams (2002), o risco deve ser compreendido como uma dimensão subjetiva, que depende da análise que cada sujeito faz das situações, atendendo às suas experiências passadas, ao tipo de recompensa percebida e à propensão individual para enfrentar desafios. O risco pode também ser perspetivado como um fenómeno interativo, uma vez que as experiências, opiniões e sentimentos dos outros influenciam a análise que o sujeito faz da situação (Adams, 2002; Sandseter, 2010).

Nessa linha de pensamento, o brincar arriscado pode ser percebido como uma oportunidade para as crianças testarem limites, assumirem desafios e experimentarem algo inédito, lidando com a possibilidade de dano ou perda (Ball, 2002; Stephenson, 2003). Ainda, o brincar arriscado assume-se como uma forma emocionante, assustadora e entusiasmante de brincar físico, que envolve incerteza e procura por aventuras nas experiências do dia a dia (Sandseter, 2010; Smith, 1998).

Apter (2007) defende que a procura de desafios por parte das crianças é motivada pela possibilidade de experienciar elevados níveis de estimulação positiva, que envolvem sentimentos de felicidade, entusiasmo, orgulho, medo e ansiedade. Apesar de aparentemente contraditórios, são esses sentimentos que fazem com que o risco seja tão cativante, levando a que as crianças persistam na tarefa, superem o medo e vivam o entusiasmo quando dominam uma nova competência (Apter, 2007; Sandseter, 2009b, 2009c; Smith, 1998). 
Nesse sentido, torna-se possível considerar que a vivência de experiências de brincar arriscado apresenta benefícios para o desenvolvimento, estimulando a criança a mobilizar estratégias de resolução de problemas, que potenciam um maior conhecimento sobre as suas capacidades e limites. Ainda, o confronto com desafios permite que a criança supere barreiras físicas, cognitivas e emocionais, num ambiente controlado e de suporte, em que a possibilidade de errar é prevista e aceite (Tovey, 2011). Segundo diferentes autores, o contacto com o risco facilita ainda o desenvolvimento de atitudes de persistência e de empreendedorismo, levando à interpretação dos problemas como desafios, em que se treina o inesperado e se tira prazer da sua resolução (Gill, 2010; Stephenson, 2003; Tovey, 2011).

A valorização do brincar arriscado é também defendida pelo Conselho Nacional de Educação (CNE, Portugal) que, em 2011, apresentou uma recomendação relacionada com a importância da educação para o risco. Nesse documento, é referido que a perceção exagerada do risco conduz a uma vigilância excessiva e a comportamentos autoprotetores que podem degradar a qualidade de vida. Assume-se que a noção de risco não pode ser vista apenas como ameaça à saúde e ao bem- estar do indivíduo, relacionando-se também, de forma positiva, com atitudes de empreendedorismo, inovação e aventura. Importa "compreender o risco, saber geri-lo e minimizá-lo e promover na escola uma cultura onde a consciência de risco não seja tão exagerada que leve à paralisia, nem tão reduzida que conduza à irresponsabilidade". Nesse sentido, a escola deve educar para o risco, apresentando-o "não só como indicador da probabilidade de algo correr mal, mas também como indicador de sucesso em empreendimentos e iniciativas pessoais" (CNE, 2011).

\section{CATEGORIAS DO BRINCAR ARRISCADO}

A necessidade de compreender com maior profundidade as implicações do risco para o desenvolvimento e aprendizagens da criança e de identificar quais os fatores que influenciam essas experiências tem instigado diferentes autores a investir na temática do risco no brincar, com recurso a diferentes quadros e metodologias de análise (Little; Eager, 2010; Little, Wyver; Gibson, 2011).

Dentro dessa linha de investigação, destaca-se o trabalho de Sandseter (2007, 2009a), que procurou categorizar os diferentes tipos de risco presentes no brincar, observando crianças em dois contextos de jardim de infância noruegueses. Para além das observações, a investigadora entrevistou profissionais e crianças entre 4 e 5 anos. Procurando perceber que tipo de brincar envolvia risco, a entrevista decorreu a partir da discussão de diferentes situações (referidas tanto pelos entrevistados como pela investigadora), com o objetivo de perceber de que forma é que profissionais e crianças avaliavam o risco e quais as brincadeiras que as crianças tinham nos diferentes contextos. Os dados obtidos em observações e entrevistas foram cruzados com notas de campo e foi pedido a um especialista que avaliasse a sua representatividade.

Sandseter (2007) definiu seis categorias de risco, envolvendo a altura, a velocidade, as ferramentas e elementos perigosos, o jogo de luta e perseguição e a possibilidade de desaparecer/deixar de ser visto. 
$\mathrm{Na}$ categoria altura elevada, trepar foi o comportamento mais vezes mencionado como sendo arriscado, seguido do saltar de sítios altos. Para as crianças, essas ações envolvem medo e excitação e também são consideradas arriscadas pelos adultos.

A velocidade elevada foi definida enquanto categoria de risco, sobretudo em virtude do carácter imprevisível dos comportamentos que lhe estão associados (e.g. andar de bicicleta a grande velocidade comporta o risco de colidir contra algo ou alguém).

A relevância dessas duas variáveis (velocidade e altura) é também corroborada por Stephenson (2003), que as descreve como características que despoletam, simultaneamente, níveis elevados de entusiasmo e medo nas crianças, fazendo com que estas sintam que estão à beira de perder o controlo da situação.

$\mathrm{O}$ uso de ferramentas como martelos, facas e serrotes constituiu um tipo de risco pouco consensual entre as crianças. Algumas consideraram que essas experiências não apresentavam riscos, enquanto outras reconheceram possíveis consequências negativas na sua utilização. Por sua vez, os adultos assumiram o risco presente nesse tipo de atividades, afirmando que era dada especial atenção às crianças durante as ocorrências.

O brincar perto de elementos perigosos, como fogueiras ou precipícios, também não foi unânime, existindo crianças que reconheciam o risco e outras não. Os adultos consideraram que as atividades inseridas nessa categoria envolviam um risco elevado.

O jogo de luta e perseguição (e.g. brincar à luta com paus, luta corpo a corpo) foi defendido pelas crianças como sendo uma atividade muito divertida, ainda que algumas reconhecessem algum risco. Os profissionais defenderam, na sua maioria, que essas atividades não envolviam muito risco. Marques (2010) considera que o jogo de luta é um importante meio de comunicação entre as crianças, oferecendo oportunidades para o treino de competências de cooperação, negociação e resolução de problemas. No mesmo sentido, Jarvis (2010) refere que o jogo de luta potencia o desenvolvimento de papéis sociais e de género, ao facilitar a criação de experiências partilhadas, pautadas tanto pela competição como pela colaboração.

Por último, o brincar que conduz à possibilidade da criança desaparecer, perder-se ou deixar de ser vista pelo adulto é vivido pelos mais novos como algo que desperta excitação, alegria e medo, ainda que os profissionais dos jardins de infância não a encarem como sendo perigosa.

No Quadro 1 apresenta-se de forma sintetizada as diferentes categorias de risco e os comportamentos que lhe estão associados.

\section{PAPEL DO ADULTO NO BRINCAR ARRISCADO}

O entusiasmo e o interesse demonstrado pelo adulto em relação aos espaços naturais, reconhecendo-os como contextos de aprendizagem e crescimento, têm implicações no investimento que a criança introduz em suas atividades. $\mathrm{Na}$ mesma linha de pensamento, a avaliação que o adulto faz das situações de brincar arriscado e a sua própria predisposição para o risco irá influenciar, de forma 
Quadro 1 - Categorias e subcategorias do brincar arriscado

\begin{tabular}{|c|c|c|}
\hline Categorias & Risco & Subcategorias \\
\hline Altura elevada & $\begin{array}{l}\text { Lesão derivada } \\
\text { da queda }\end{array}$ & $\begin{array}{l}\text { Trepar } \\
\text { Saltar de superfícies fixas ou flexíveis } \\
\text { Baloiçar em estruturas elevadas } \\
\text { Ficar pendurado a uma altura elevada }\end{array}$ \\
\hline Velocidade elevada & $\begin{array}{l}\text { Colisão com algo } \\
\text { ou alguém }\end{array}$ & $\begin{array}{l}\text { Baloiçar a uma velocidade elevada } \\
\text { Escorregar (sliding) a uma velocidade elevada } \\
\text { Correr a uma velocidade elevada } \\
\text { Andar de bicicleta/skate a uma velocidade elevada }\end{array}$ \\
\hline Ferramentas perigosas & Lesão ou ferimento & $\begin{array}{l}\text { Ferramentas (facas, serrotes, machados, } \\
\text { martelos) e cordas }\end{array}$ \\
\hline $\begin{array}{l}\text { Jogo de luta e } \\
\text { perseguição }\end{array}$ & $\begin{array}{l}\text { Lesão ou ferimento } \\
\text { causado por } \\
\text { outra criança }\end{array}$ & Luta corpo a corpo ou com paus \\
\hline $\begin{array}{l}\text { Desaparecer/ perder-se/ } \\
\text { deixar de ser visto }\end{array}$ & $\begin{array}{l}\text { Sair da supervisão } \\
\text { dos adultos } \\
\text { Perder-se sozinha }\end{array}$ & $\begin{array}{l}\text { Ir explorar o espaço sozinho } \\
\text { Brincar sozinho em espaços não familiares }\end{array}$ \\
\hline Elementos perigosos & $\begin{array}{l}\text { Possibilidade de cair } \\
\text { de ou para algo }\end{array}$ & $\begin{array}{l}\text { Desfiladeiros } \\
\text { Águas profundas } \\
\text { Fogueiras }\end{array}$ \\
\hline
\end{tabular}

Fonte: adaptado de Sandseter (2009a, p. 7).

significativa, o tipo de desafios a que a criança tem acesso (Sandseter, 2009c). Quando um adulto é capaz de gerir o risco de forma flexível, reconhecendo o seu impacte no desenvolvimento, é possível prever que as vivências de desafio, por parte da criança, serão facilitadas e incentivadas (Sandseter, 2010; Stephenson, 2003).

Importa realçar que a necessidade de dar espaço à criança para que esta teste os seus limites e tome decisões de forma autónoma, em relação àquilo que é ou não capaz de fazer, não invalidará o valor do papel do adulto nas situações de desafio, seja a observar ou a participar ativamente na atividade. Nesse sentido, Tovey (2007, p. 107) sugere que, apesar de as crianças precisarem de oportunidades para aprenderem a avaliar os riscos, as reduzidas experiências de vida que possuem fazem com que por vezes seja necessária a ajuda de uma criança mais experiente ou de um adulto para lidar com a situação.

O risco deve ser percebido como uma componente importante da relação pedagógica que o adulto estabelece com a criança, sendo necessário analisar as situações de brincar arriscado atendendo à perspetiva da criança (Smith, 1998).

Com efeito, o receio de que algo negativo possa acontecer não pode ser tão dominante a ponto de conduzir o adulto a atitudes de supervisão excessiva que não permitam a vivência de qualquer tipo de desafio ou risco (Sandseter, 2009c; Smith, 1998). Importa aceitar que os arranhões e as feridas fazem parte do crescimento, sendo impossível e indesejável garantir a segurança absoluta das crianças. Ainda que a supervisão dos adultos diminua a probabilidade de ocorrerem acidentes, a 
proteção deve ser fornecida de um modo equilibrado, possibilitando que as crianças desenvolvam as suas próprias estratégias de resolução de problemas (Bilton, 2010; Sandseter, 2010; Waller, 2011). A atuação do adulto deve ser ponderada em virtude do conhecimento que se tem das competências, interesses e motivações da criança, refletindo-se em torno dos ganhos para o desenvolvimento que podem advir tanto do fracasso como do sucesso na resolução do desafio (Christensen; Mikkelsen, 2008; Smith, 1998).

\section{METODOLOGIA}

A investigação realizada baseou-se numa metodologia qualitativa, utilizando-se a entrevista semiestruturada como técnica de recolha de dados preferencial. O guião de entrevista foi pensado em virtude das dimensões enfatizadas pela literatura e a sua estrutura foi articulada com um conjunto de imagens representativas de experiências de brincar arriscado. A escolha das imagens foi inspirada nas categorias de brincar arriscado de Sandseter (2007,2009a) - altura elevada, velocidade elevada, jogo de luta e perseguição, ferramentas perigosas, possibilidade de desaparecer ou deixar de ser visto, elementos perigosos.

Para cada categoria foram escolhidas três imagens (totalizando dezoito delas), e cada uma foi acompanhada por uma legenda com a finalidade de dar mais detalhes acerca das situações e de procurar garantir que a avaliação das educadoras se remetia para as dimensões de risco em análise. A sequência de apresentação das imagens foi aleatória em cada entrevista, no intuito de minimizar a possível influência que umas imagens poderiam exercer sobre as outras.

Durante a entrevista, as imagens davam o mote, e a discussão desenvolvia-se em torno de quatro aspetos centrais: de que forma o risco era percebido e como ele podia variar, qual seria o comportamento da educadora numa situação semelhante (permissão ou proibição) e de que forma as experiências retratadas tinham influência no nível das aprendizagens e no desenvolvimento da criança. Para que fosse possível perceber com maior exatidão de que forma variava o nível de risco atribuído às diferentes situações, foi pedido às educadoras para registarem numa escala de 0 a 4 - em que 0 significava ausência total de risco e 4 risco elevado/perigo - qual o nível de risco percebido nas diferentes situações. Para além da discussão acerca das imagens, foram também colocadas questões mais gerais, que tinham como objetivo perceber até que ponto as crianças eram vistas pelas educadoras como sendo confiáveis e competentes para lidar com o risco e de que forma é que as educadoras perspetivam o seu comportamento em relação à promoção de desafios no quotidiano.

Neste artigo iremos apenas apresentar os resultados obtidos em relação às seguintes dimensões de análise: (1) De que forma as educadoras avaliam diferentes situações de brincar arriscado? (2) Que dimensões influenciam a avaliação que as educadoras fazem das situações de brincar arriscado? (3) Como as educadoras percebem a influência do risco no desenvolvimento e nas aprendizagens? 


\section{PARTICIPANTES}

A investigação realizada envolveu 13 educadoras de infância da região centro de Portugal, a trabalhar em diferentes instituições de ensino (públicas, privadas com fins lucrativos e privadas sem fins lucrativos). A escolha destas foi feita por conveniência de proximidade e, apesar de não se terem estipulado critérios de seleção, procurou-se que todas as educadoras estivessem a trabalhar com um grupo de crianças com idades entre 3 e 5 anos na altura da entrevista. As educadoras entrevistadas apresentam idades compreendidas entre 28 e 55 anos e os anos de serviço variam entre 5 e 32 anos.

\section{RECOLHA E ANÁLISE DOS DADOS}

As entrevistas foram realizadas nos contextos de trabalho das educadoras, em locais calmos, sem excessivas interrupções e com algum conforto, potenciando-se assim o espírito de abertura e de partilha. Para facilitar a recolha dos dados e para que se prestasse maior atenção ao diálogo, as conversas foram gravadas em formato áudio e posteriormente transcritas pela investigadora. De modo geral, a gravação das entrevistas pareceu não exercer grande influência na atitude e respostas das educadoras, sendo que o desconforto e o nervosismo que poderiam existir numa fase inicial foram desaparecendo ao longo da conversa.

O tratamento dos dados foi feito com o apoio do software webQDA, um programa que permite a "análise de dados não numéricos e não estruturados num ambiente colaborativo e distribuído com base na Internet" (Neri de Souza; Costa; Moreira, 2011, p. 19). O webQDA apoia o investigador nas diferentes fases do processo de investigação, permitindo trabalhar e questionar os dados de forma rápida e flexível.

\section{1) DE QUE FORMA AS EDUCADORAS AVALIAM DIFERENTES SITUAÇÕES DE BRINCAR ARRISCADO?}

A necessidade de atribuir um valor (entre 0 e 4 ) a cada situação de brincar arriscado promoveu a reflexão em torno da situação em análise, considerando-se diferentes fatores úteis para compreender o modo como cada educadora avaliava o risco.

Em virtude da análise da frequência de respostas obtidas nos diferentes níveis de risco, foi possível perceber que 10, entre 18 imagens apresentadas, são avaliadas com "muito risco" ou "risco elevado/perigo" pela maioria das educadoras. Entre essas, destacam-se imagens relacionadas com as categorias de altura elevada, possibilidade de desaparecer ou deixar de ser visto e contacto com elementos perigosos. Ainda, perante as imagens apresentadas, a maioria das educadoras referiu que não permitiria que tal situação acontecesse, sobretudo, nas experiências que envolviam a utilização de ferramentas, possibilidade de sair do campo de supervisão do adulto e contacto com elementos perigosos. 
A análise das tendências de resposta das educadoras quanto ao nível de risco presente nas imagens e a reflexão em torno das suas opiniões relativas à possibilidade de permitir as experiências de brincar arriscado permite afirmar que essas duas fontes de informação são convergentes, apontando para visões desfavoráveis em torno das experiências de brincar arriscado.

\section{2) QUE DIMENSÕES INFLUENCIAM A AVALIAÇÃO QUE AS EDUCADORAS FAZEM DAS SITUAÇÕES DE BRINCAR ARRISCADO?}

A reflexão em torno das imagens revelou a complexidade associada à avaliação das situações de brincar arriscado. Muitas vezes, as educadoras consideraram diferentes variáveis na interpretação que faziam das situações, suscitando o interesse da investigadora em perceber quais as dimensões que faziam variar as perceções de risco e a consequente aceitação/proibição das situações retratadas.

Nesse sentido, foi realizada uma análise de conteúdo em relação a essa questão, e os dados obtidos foram organizados em subcategorias e atributos que se apresentam no Quadro 2.

Quadro 2-Dimensões que influenciam as perceções de risco

\begin{tabular}{|l|l|}
\hline \multicolumn{1}{|c|}{ Subcategorias } & \multicolumn{1}{c|}{ Atributos } \\
\hline Contexto & $\begin{array}{l}\text { Presença do adulto } \\
\text { Características do espaço } \\
\text { Número de crianças }\end{array}$ \\
\hline Ação & $\begin{array}{l}\text { Modificação do brincar } \\
\text { Objetos da ação }\end{array}$ \\
\hline Criança & $\begin{array}{l}\text { Conhecimento/competência } \\
\text { Nível de desenvolvimento/idade } \\
\text { Familiaridade } \\
\text { Prazer/divertimento }\end{array}$ \\
\hline Adulto & $\begin{array}{l}\text { Medos } \\
\text { Atitudes extremadas } \\
\text { Características pessoais } \\
\text { Controlo/conforto } \\
\text { Cultura }\end{array}$ \\
\hline
\end{tabular}

Fonte: Banco de dados da pesquisa.

Elaboração da autora.

\section{Contexto}

$\mathrm{Na}$ avaliação que as educadoras fizeram das imagens, a presença do adulto revelou-se como sendo um fator muito influente. Na maioria das entrevistas, a presença do adulto foi vista como elemento atenuante do risco, sendo que em alguns casos a sua ausência impediria que a situação de brincar arriscado se desenrolasse. Nesse sentido, atente-se à transcrição apresentada a seguir: 
Amélia: ${ }^{1}$ Com um adulto a ver não tinha risco. Mesmo que o adulto só estivesse a ver. Comigo lá eles podem fazer tudo.

Investigadora: Sem o adulto a ver?

Amélia: Não fazem nada que eu não deixo (discussão sobre imagem relativa à categoria possibilidade de desaparecer).

Percebendo a acentuada ênfase dada à necessidade de o adulto estar presente, questionámos as educadoras em relação ao comportamento adotado pelo adulto nas situações de brincar arriscado. A supervisão foi uma das opções mais frequentes, surgindo 128 vezes, no total das entrevistas. A par desta, foi também referida a possibilidade de emitir alertas, dar conselhos ou ajudar diretamente a criança a lidar com a situação.

Aspetos relacionados com o conhecimento que se tem dos espaços e as suas características (e.g. tipo de piso, existência de obstáculos) foram também fatores de ponderação mencionados pelas educadoras. A possível existência de perigos, como poços ou precipícios, e a definição de fronteiras físicas apresentaram-se como variáveis importantes, associadas à necessidade de prevenir lesões ou acidentes.

Luísa: Só permitia se fosse um espaço fechado, que eu conhecesse e visse que não oferecia perigos (discussão sobre imagem relativa à categoria possibilidade de desaparecer).

Importa destacar que, por vezes, a transformação do contexto no intuito da proteção foi vista como medida que empobrecia o brincar da criança, ainda que pudesse aumentar a sua segurança. Consideramos que esse aspeto é muito interessante, evidenciando que os obstáculos nem sempre são identificados pelas educadoras como potenciadores exclusivos de perigos, sendo também reconhecidos como importantes estímulos para o brincar.

Investigadora: E há alguma forma de diminuir o risco?

Edite: Desbastar um pouco os arbustos, mas depois também tira a graça, porque já fica um espaço mais amplo (discussão sobre imagem relativa à categoria possibilidade de desaparecer).

O número de crianças envolvidas na atividade revelou-se também como um fator influente nas perceções de risco das educadoras. Apesar de ter sido referido em relação a várias categorias, nas imagens relativas às ferramentas essa variável destacou-se, considerando-se que a presença de várias crianças poderia conduzir a uma maior distração por parte daqueles que estavam a utilizar as ferramentas. $\mathrm{O}$ número de crianças também influencia o grau de controlo que o adulto tem sobre a situação.

1 O nome atribuído a todas as educadoras entrevistadas é fictício. 
Ação

As características da ação podem também ser consideradas dimensões com um papel significativo nas perceções de risco. Para as educadoras, a permissão de determinadas experiências e a aceitação do risco implica alterações em relação ao que é representado nas imagens (modificação do brincar). Nesse sentido, algumas educadoras consideraram que a exploração de determinados elementos, como o fogo, só seria aceite em moldes diferentes, nos quais a criança assumiria um papel mais passivo e o adulto lideraria a atividade.

Mafalda: Podia permitir em moldes laboratoriais, num contexto controlado, relacionando com a exploração da ciência. As crianças estariam mais como observadoras e o adulto a demonstrar (discussão sobre imagem relativa à categoria elementos perigosos).

Aspetos relacionados com a intensidade da brincadeira interferem de forma significativa na opinião das educadoras em relação às imagens de brincar arriscado, sendo que na maioria das vezes foi referido que a permissão das experiências de risco exigiria a diminuição da velocidade ou da altura.

Por sua vez, a posição da criança (e.g. em pé ou sentada) e o tipo de objetos/ equipamentos utilizados são também tidos em conta no processo de avaliação. Materiais que promovam a segurança, como a utilização de luvas no contacto com as ferramentas, calçado apropriado para correr ou para andar numa zona escorregadia, capacetes e joalheiras para andar de bicicleta ou objetos moles para brincar à luta são exemplos de alguns aspetos mencionados pelas educadoras para reduzir o risco.

Será pertinente realçar que em algumas situações as estratégias identificadas para reduzir o risco passavam pela eliminação de objetos da ação ou de elementos que se revelam necessários para a realização da atividade e para a existência de uma componente de risco ou desafio (e.g. retirar paus, serrote, faca, criança observar o adulto).

Teresa: Se calhar, não ia deixar que andassem com tanta velocidade, mas iria permitir. Se calhar, dizia: "Vamos caminhar, vamos sentir a chuva, vamos pisar com força a água”. Se calhar, o que eu faria era arranjar outro tipo de estímulos (discussão sobre imagem relativa à categoria velocidade elevada).

\section{Criança}

$\mathrm{Na}$ análise das imagens, o conhecimento que as educadoras possuem sobre as crianças foi identificado como um aspeto importante, que pode influenciar a decisão do adulto em relação à permissão/proibição de determinadas experiências de risco. Essa ideia pode ser associada à perceção que as educadoras têm da criança como alguém competente para enfrentar e lidar com o risco. 
Mafalda: Este objeto exige uma grande coordenação oculomanual que uma criança pequena não tem (discussão sobre imagem relativa à categoria ferramentas perigosas).

Ainda foram mencionados fatores relacionados com a familiaridade da criança com a situação em análise (e.g. utilizar ferramentas) e considerados aspetos relacionados com o prazer, divertimento e confiança potenciados pelo brincar arriscado.

Júlia: Uma pessoa também avalia pela expressão das crianças. Elas parecem muito felizes e à vontade no que estão a fazer (discussão sobre a imagem relativa à categoria jogo de luta e perseguição).

\section{Adulto}

$\mathrm{Na}$ sequência da ideia base deste trabalho, relacionada com a importância e a influência do educador no tipo de experiências a que a criança tem acesso, verificámos, com base na análise das entrevistas, que os medos, gostos, necessidades e valores culturais que caracterizam o adulto podem ser identificados como dimensões importantes no processo de avaliação do risco.

A gestão e a ponderação entre os receios pessoais e as vantagens que as experiências de brincar arriscado podem trazer para a criança podem ser uma tarefa árdua para o adulto que, por vezes, opta por adaptar a situação, no intuito de reduzir o seu medo, ansiedade e preocupação.

Edite: Às vezes me questiono sobre essa dualidade, entre riscos e vantagens, mas acaba sempre por ganhar o meu receio dos riscos (discussão sobre a imagem relativa à categoria jogo de luta e perseguição).

Maria João: Isto é mesmo uma limitação minha. Eu não vejo mal nenhum nisto. Ele está a uma distância considerável, tem um pau, mas acho que diria "algum risco". São fobias minhas que tenho de ultrapassar (discussão sobre a imagem relativa à categoria elementos perigosos).

Será pertinente realçar que alguns dos medos partilhados possuem uma componente demasiado dramática ou fatalista, prejudicial para uma avaliação ponderada da situação (e.g. receio de que a criança dê uma volta de $360^{\circ}$ no baloiço).

Anabela: Eu às vezes penso que o simples cantar os parabéns já exige cuidado e peço à criança para que não se aproxime muito e sopre detrás (discussão sobre a imagem relativa à categoria elementos perigosos).

Do mesmo modo, verificaram-se também referências às características pessoais das educadoras, surgindo várias vezes expressões como "não gosto", "não acho graça" ou "faz-me confusão", ilustrando a ideia de que, por vezes, no processo de avaliação do risco é sobretudo tido em conta aquilo que o educador pensa ou quer, e não tanto aquilo que a criança prefere ou que é importante para ela. 
As necessidades de controlo e conforto por parte do adulto apresentam-se também como dimensões que influenciam a avaliação que as educadoras fazem do brincar arriscado. Com efeito, na tentativa irrealizável de garantir a segurança plena das crianças, manifestaram-se visões pouco flexíveis e centradas no adulto.

Edite: Numa árvore, num espaço livre, não tenho a situação tão bem controlada. Numa estrutura de ginástica controlo melhor as variáveis do salto (discussão sobre a imagem relativa à categoria altura elevada).

Teresa: Não é necessário viver essa experiência com essa intensidade toda (discussão sobre a imagem relativa à categoria altura elevada).

Por último, o contexto cultural no qual as educadoras estão inseridas é uma dimensão basilar que importa ter em conta na análise das perceções de risco. Os valores e comportamentos socialmente previstos têm uma influência significativa no modo como se perspetivam as experiências de infância, sendo difícil contrariar o peso de hábitos, estereótipos ou preconceitos que se enraizaram na prática profissional e na sociedade (e.g. jogo de luta e perseguição visto com conotação negativa, uma vez que se considera que as crianças devem ser amigas umas das outras).

\section{2) COMO AS EDUCADORAS PERCEBEM A INFLUÊNCIA DO RISCO NO DESENVOLVIMENTO E NAS APRENDIZAGENS?}

A análise das respostas das educadoras em relação ao impacte das experiências de brincar arriscado no desenvolvimento e aprendizagens das crianças foi feita à luz das áreas de conteúdo definidas pelas Orientaçôes curriculares para a educação pré-escolar (Ministério da Educação, Portugal, 1997).

Nesse sentido, dentro da área da formação pessoal e social, as educadoras referiram que as experiências que envolviam altura, o uso de ferramentas, a velocidade e a possibilidade de desaparecer promoviam a autonomia das crianças e forneciam um importante sentimento de liberdade. Por meio dessas experiências era também possível desenvolver a autoestima e a confiança, uma vez que lhes era dada a possibilidade de testarem competências e aprendizagens, resolverem problemas e tomarem decisões.

Edite: Acho que é importante para as crianças sentirem que nós temos confiança nelas para lhes darmos mais autonomia, mais autoconfiança, mais capacidade de interagirem com outras crianças de uma forma mais livre, sem estarem controladas (categoria possibilidade de desaparecer).

Nas palavras de Edite está presente uma ideia importante, relacionada com a interação entre pares. Na reflexão em torno dos ganhos para o desenvolvimento, algumas educadoras referiram que as experiências que envolvem o jogo de luta e perseguição, a velocidade e altura elevadas e a possibilidade de desaparecer criam oportunidades para a cooperação entre pares, para o treino de competências de liderança e para a partilha de experiências e sentimentos que fomentam as amizades. 
Maria João: Mas também já percebi que em muitas situações se desenvolvem atitudes de cooperação. Interagem muito entre eles para perceber como é que podem resolver o problema (categoria possibilidade de desaparecer).

$\mathrm{Na}$ área da expressão e comunicação, a referência aos benefícios motores, como o desenvolvimento de competências de equilíbrio, destreza e agilidade (velocidade e altura), a coordenação oculomanual (ferramentas), o conhecimento do corpo (jogo de luta e perseguição) e a orientação espacial (possibilidade de desaparecer), surgiu em todas as categorias de brincar arriscado. Duas educadoras entrevistadas mencionaram também a possibilidade de desenvolver a matemática e a literacia por intermédio das experiências de desafio e risco.

Rita: A área motora, o relacionamento com o outro, a negociação do espaço de cada um, a quantidade de força que aplicam (categoria jogo de luta e perseguição).

No domínio do conhecimento do mundo, foram associadas aprendizagens relacionadas com as experiências ligadas com as categorias elementos perigosos, ferramentas perigosas e possibilidade de desaparecer. Realçando-se o impacte dessas experiências na promoção da curiosidade, criatividade e imaginação das crianças, a maioria das educadoras considerou que o contacto com espaços naturais leva a criança a colocar questões e a participar na construção do seu próprio conhecimento. Dessa forma, torna-se possível explorar processos relacionados com a ciência (e.g. química, física) e com a natureza (e.g. fauna e flora).

Júlia: As ciências (que objetos flutuam e quais é que não flutuam, as medidas), as noções ecológicas, como a separação do lixo e a necessidade de preservar o ambiente (categoria elementos perigosos).

Importa referir que o reconhecimento de ganhos para o desenvolvimento não foi comum a todas as educadoras entrevistadas. Para algumas participantes, em experiências relacionadas, por exemplo, com altura e velocidade elevada ou jogo de luta e perseguição não foi identificado qualquer ganho para o desenvolvimento ou potencial de aprendizagem.

Amélia: É natural deles. É mais uma interação que eles têm uns com os outros. Aprender não aprendem grande coisa, mas é intrínseco nelas (categoria jogo de luta e perseguição).

\section{REFLEXÕES FINAIS E PISTAS PARA INTERVENÇÃO}

A investigação realizada permitiu explorar uma área pouco desenvolvida no contexto português, suscitando a reflexão em torno de questões que podem ser pertinentes para orientar, avaliar e melhorar as ofertas educativas nos contextos de educação pré-escolar. Sem almejar a generalização dos dados apresentados, 
gostaríamos de salientar algumas ideias que emergiram da análise das entrevistas e que se podem revelar pertinentes para compreender a temática do risco no brincar.

As experiências de brincar arriscado foram percebidas pela maioria das educadoras como situações pautadas por elevados níveis de risco, que dificilmente seriam permitidas nos contextos de trabalho das participantes. A presença de elementos conotados, por si só, como "perigosos" suscita elevados níveis de ansiedade e medo, que prejudicam as interações no exterior. Nesse sentido, apesar de serem reconhecidos possíveis ganhos por meio das experiências de risco, estes não se consubstanciam como argumento suficientemente forte para conduzir a atitudes de aceitação e promoção de experiências de desafio por parte de algumas educadoras. À semelhança daquilo que Tovey (2010) encontrou no seu estudo com profissionais ingleses, podemos considerar que existe um conflito entre aquilo que as educadoras consideram que é importante para as crianças e as suas próprias angústias e receios, optando mais vezes por impedir ou restringir a brincadeira em virtude da possibilidade de lesão.

Contudo, na investigação realizada por Sandseter (2009c, 2009d), na Noruega, encontramos uma atitude distinta em relação ao brincar arriscado, verificando-se que um grande número de experiências de desafio ocorre quando os adultos não estão a ver, sendo dado espaço às crianças para que circulem livremente, se confrontem com problemas a resolver e vivam experiências de brincar arriscado.

Nessa linha de pensamento, torna-se possível considerar que a dificuldade das educadoras entrevistadas para lidar com situações de brincar arriscado representa um fenómeno complexo que não pode ignorar a importância e a influência da cultura. A forma como se perspetivam as competências da criança é influenciada por mentalidades, valores, estereótipos e interesses socioeconómicos que vão para além do espaço do jardim de infância e caracterizam as sociedades.

A conceção de criança como ser vulnerável e dependente, apesar de extravasar fronteiras políticas e territoriais, é interpretada e aplicada de forma muito distinta nos vários países, sendo importante adotar uma atitude flexível na interpretação das situações de brincar arriscado. As diferenças de género, por exemplo, poderão ser uma dimensão importante a considerar em investigações futuras, colocando-se a hipótese de que educadores de infância do sexo feminino e masculino apresentarão diferentes sensibilidades perante o risco, permitindo experiências distintas às crianças. Nesta investigação apenas foram auscultadas mulheres, o que constitui uma limitação do estudo. Em contrapartida, o tipo de expetativas sociais em relação às brincadeiras de meninos e meninas poderá influenciar a aceitabilidade de determinadas situações (e.g. será que o jogo de luta e perseguição é igualmente aceite em rapazes e raparigas?), dimensão que também não foi explorada neste trabalho.

A referência a estudos desenvolvidos noutros países, como a Noruega, a Inglaterra ou a Austrália (e.g. Little; Eager, 2010; Sandseter, 2009a; Tovey, 2010), não deve ser vista sob uma perspetiva de comparação linear, reconhecendo-se o papel de dimensões sociológicas na construção de conceções sobre o risco no brincar. Nesse sentido, as investigações internacionais podem servir de referência e contribuir para o desenvolvimento de uma abordagem que terá de ser contextualizada à realidade de cada país/cultura. 
Se a investigação científica na área tem vindo a evidenciar que o brincar arriscado representa uma mais-valia para o desenvolvimento das crianças, será pertinente considerar essa temática como uma componente importante a abordar no contexto de formação inicial e continuada dos profissionais, garantindo uma maior valorização e sustentação teórica em torno dessas experiências.

Será também relevante desenvolver espaços de discussão nas equipas de trabalho, em que se partilhem dúvidas, experiências e ideias acerca das experiências de brincar arriscado, potenciando-se a construção de um referencial pedagógico comum e culturalmente significativo, que sustente as práticas e ajude as educadoras a experimentar o risco. Nesse processo, reconhecer a importância do papel do educador nas experiências de brincar arriscado, orientando e acompanhando as crianças em determinadas experiências (e.g. uso de ferramentas; contacto com elementos perigosos) afigura-se como algo importante para o desenvolvimento de práticas pedagógicas de qualidade. Do mesmo modo, torna-se essencial aceitar que não é possível abolir todas as fontes de risco, sendo relevante fornecer oportunidades para enfrentar desafios dentro de um ambiente controlado e familiar. Retirar os paus, as pedras, a água, os desníveis, pode diminuir o risco, mas reduz a possibilidade de viver experiências ricas, que garantam a aquisição de estratégias e competências de resolução de problemas.

Finalmente, em futuros projetos seria interessante averiguar quais as perceções dos pais e das crianças em relação ao risco no brincar, considerando que a ação do educador não pode ignorar as expectativas e visões das famílias e suas comunidades.

\section{REFERÊNCIAS}

Adams, J. Risk. London: Routledge, 2002.

Albuquerque, D.; Nóbrega, C.; Samouda, H.; Manco, L. Avaliação da obesidade e obesidade abdominal em crianças portuguesas. Acta Médica Portuguesa: Revista Científica da Ordem dos Médicos, Lisboa: Ordem dos Médicos, v. 11, n. 3, p. 169-173, maio/jun. 2012.

Apter, M. Danger: our quest for excitement. Oxford: Oneworld Publications, 2007.

BALL, D. Playgrounds: risks, benefits and choices. London: Middlesex University; London: Health and Safety Executive (HSE), 2002. Disponível em: <https://eprints. mdx.ac.uk/4990/1/crr02426.pdf>. Acesso em: 10 jul. 2014.

BiLton, H. Outdoor learning in the early years: management and innovation. 3. ed. Oxon: Routledge, 2010.

Christensen, P.; Mikkelsen, M. Jumping off and being careful: children's strategies of risk management in everyday life. Sociology of Health E Illness, Oxford: Foudation for the Sociology of Health \& Ilness/Blackwell Publishing, v. 30, n. 1, p. 1-19, 2008.

CNE - Conselho Nacional de Educação. Recomendação n. 5/2011. Educação para o risco. Diário da República, n. 202, 20 out. 2011. Ministério da Educação e Ciência, Portugal. (Relatores: Arsélio Carvalho; Rosália Vargas). 
FJøRтоғт , I. Landscape as playscape: the effects of natural environments on children's play and motor development. Children, Youth and Environments, Boulder:University of Colorado, v. 14, n. 2, p. 21-44, 2004.

Gill, T. Sem medo: crescer numa sociedade com aversão ao risco. Cascais: Princípia, 2010. JARVIS, P. "Born to play": the biocultural roots of rough and tumble play, and its impact upon young children's learning and development. In: Broadhead, P.; Howard, J.; Wood, E. (Orgs.). Play and learning in the early years. London: Sage Publications, 2010. Little, H; Eager, D. R. challenge and safety: implications for play quality and playground design. European Early Childhood Education Research Journal, London: Routldege, v. 18, n. 4, p. 497-513, Dec. 2010.

.; Wyver, S.; Gibson, F. The influence of play context and adult attitudes on young children's physical risk-taking during outdoor play. European Early Childhood Education Research Journal, London: Routldege, v. 19, n. 1, p. 113-131, Mar. 2011.

Marques, A. Jogo de luta ou luta a sério? Como distinguir para decidir? Cadernos de Educação de Infância, Lisboa: Associação de Profissionais de Educação de Infância, Lisboa: APEI, v. 90, p. 24-30, 2010.

MinistéRIO DA Educação (Ed.). Orientações curriculares para a educação pré-escolar. Lisboa: Ministério da Educação, 1997.

Moreno, D. Jogo de actividade física e a influência de variáveis biossociais na vida quotidiana de crianças em meio urbano. 2009. 609f. Tese (Doutoramento em Motricidade Humana) - Faculdade de Motricidade Humana da Universidade Técnica de Lisboa, Lisboa, 2009.

Neri de Souza, F.; Costa, A.; Moreira, A. Questionamento no processo de análise de dados qualitativos com apoio ao software WebQDA. EduSer - Revista de Educação, Bragança: Instituto Politécnico de Bragança, v. 3, n. 1, p. 19-30, 2011.

NEto, C. Tempo \& espaço de jogo para a criança: rotinas e mudanças sociais. In: (Org.). O jogo e o desenvolvimento da criança. Lisboa: Edições FMH, 1997. p. 10-22.

A mobilidade do corpo na infância e desenvolvimento urbano: um paradoxo da sociedade moderna. In: Rodrigues, D. (Org.). O corpo que (des) conhecemos. Lisboa: Edições FMH, 2005.

OMS - Organização Mundial de Saúde. European Charter on counteracting Obesity. WHO European Ministerial Conference on Counteracting Obesity. Istambul, Turquia, 15-17 nov., 2006. Disponível em: <http://www.euro.who.int/_data/assets/ pdf_file/0009/87462/E89567.pdf>. Acesso em: 9 jul. 2014.

Rito, A.; Breda, J. Prevalence of childhood overweight and obesity in Portugal: the national nutrition surveillance system. Obesity Revierws, Hoboken, NJ: Wiley, v. 11, n. 1, p. 428, 2010.

SAndseter, E. Categorizing risky play: how can we identify risk-taking in children's play? European Early Childhood Education Research Journal, London: Routldege, v. 15, n. 2, p. 237-252, jun. 2007. 
Characteristics of risky play. Journal of Adventure Education and Outdoor Learning, London: Institute for Outdoor Learning; Routledge, v. 9, n. 1, p. 3-21, jun. 2009a.

. Children's expression of exhilaration and fear in risky play. Contemporary Issues in Early Childhood, Oxford: Symposium Journals, v. 10, n. 2, p. 92-105, 2009 b.

Risky play and risk management in Norwegian preschools: a qualitative observational study. Safety Science Monitor, London: Elsevier, v. 13, n. 1, p. 1-12, 2009c.

. Affordances for risky play in preschool: the importance of features in the play environment. Early Childhood Education Journal, New York: Springer Netherlands, v. 36, p. 439-446, 2009d.

. Scaryfunny: a qualitative study of risky play among preschool children. 2010. 141f. Tese (Doutoramento em Filosofia) - Norwegian University of Science and Technology, Trondheim, 2010.

Sмiтн, S. Risk and our pedagogical relation to children: on playground and beyond. New York: State University of New York Press, 1998.

Stephenson, A. Physical risk-taking: dangerous or endangered? Early Years, London: Carfax Publishing, v. 23, n. 1, p. 35-43, 2003.

Thigpen, B. Outdoor play: combating sedentary lifestyles. Zero to Three, Washington: National Center for Infants, Toddlers and Families, v. 28, n. 1, p. 19-23, Sept. 2007.

Thomas, F.; Harding, S. The role of play. In: White, J. (Org.). Outdoor provision in the early years. London: Sage Publications, 2011. p. 12-22.

Tover, H. Playing outdoor: spaces and places, risk and challenges. Berkshire: Open University Press, McGraw-Hill Education, 2007.

Playing on the edge: perceptions of risk and danger in outdoor play. In: Broadhead, P.; Howard, J.; Wood, E. (Orgs.). Play and learning in the early years. London: Sage Publications, 2010. p. 79-94.

. Achieving the balance. In: White, J.(Org.). Outdoor provision in the early years. London: Sage Publications 2011. p. 86-94.

Waller, T. Adults are essential. In: White, J. (Org.). Outdoor provision in the early years. London: Sage Publications, 2011. p. 35-44.

\section{SOBRE A AUTORA}

Maria Gabriela Portugal Bento é doutoranda em educação pela Universidade de Aveiro (Portugal).

E-mail: bie.bento@gmail.com 